\title{
Hydrogen Sulfide Alleviates Senescence of Fresh-cut Apple by Regulating Antioxidant Defense System and Senescence-related Gene Expression
}

\author{
Ji-Lian Zheng ${ }^{1}$, Lan-Ying $\mathrm{Hu}^{1}$, and Kang-Di $\mathrm{Hu}^{1}$ \\ School of Biotechnology and Food Engineering, Hefei University of \\ Technology, Hefei 230009, China \\ Jun Wu \\ College of Horticulture, Nanjing Agricultural University, Nanjing 210095, \\ China
}

Feng Yang

Xuzhou Institute of Agricultural Sciences of the Xuhuai District of Jiangsu Province, Xuzhou 221131, China

\author{
Hua Zhang ${ }^{2}$ \\ School of Biotechnology and Food Engineering, Hefei University of \\ Technology, Hefei 230009, PR China
}

Additional index words. browning, ethylene, protease, reactive oxygen species

\begin{abstract}
Hydrogen sulfide $\left(\mathrm{H}_{2} \mathrm{~S}\right)$ has been identified as a multifunctional signaling molecule in plants. Here, we show that $\mathrm{H}_{2} \mathrm{~S}$ delayed postharvest senescence of fresh-cut apples (Malus $\times$ pumila) in a dose-dependent manner. Exogenous $\mathrm{H}_{2} \mathrm{~S}$ application maintained significantly higher levels of ascorbic acid, flavonoids, total phenolics, reducing sugars and soluble proteins, and lower levels of free amino acids in apple slices compared with controls. Further investigations showed that $\mathrm{H}_{2} \mathrm{~S}$ significantly reduced the accumulation of superoxide radicals, hydrogen peroxide $\left(\mathrm{H}_{2} \mathrm{O}_{2}\right)$ and malondialdehyde (MDA). Apple fruits fumigated with $\mathrm{H}_{2} \mathrm{~S}$ contained significantly higher activities of ascorbate peroxidase (APX), catalase (CAT), glutathione reductase (GR), guaiacol peroxidase (POD) and superoxide dismutase (SOD), and lower activities of lipoxygenase (LOX), phenylalanine ammonia lyase (PAL), polyphenol oxidase (PPO), and protease relative to controls. $\mathrm{H}_{2} \mathrm{~S}$ also upregulated $M d D H A R$ expression and downregulated the expression of MdLOX2, MdPG1, MdPPO, MdACO1, MdERS1, and MdETR1 in postharvest apple tissue. The present study indicates that $\mathrm{H}_{2} \mathrm{~S}$ was involved in delaying postharvest senescence of apples by acting as an antioxidant and by regulating senescence-related gene expression.
\end{abstract}

Hydrogen sulfide, similar to nitric oxide (NO) and carbon monoxide (CO), has been shown to be an endogenous gaseous signaling molecule in animal systems with multifaceted physiological functions (Wang, 2002). In plants, $\mathrm{H}_{2} \mathrm{~S}$ can be endogenously generated from cysteine and sulfite by $O$-acetylserine

Received for publication 7 Oct. 2015. Accepted for publication 31 Dec. 2015.

Funding for this work was provided by Natural Science Foundation of China (31470013, 31301820,31300133 , and 31271803), the Scientific Research Foundation for Returned Overseas Chinese Scholars (SRF for ROCS, MOE), the Natural Science Foundations of Anhui Province (11040606M85), and the Anhui Provincial Education Department (2012AJZR0028, ZD200910).

We thank Russell Jones, University of California at Berkeley, for the revision of the manuscript.

${ }^{1}$ These authors contributed equally to this work.

${ }^{2}$ Corresponding author. E-mail: hzhanglab@hfut. edu.cn. (thiol) lyase and sulfite reductase, respectively (Rausch and Wachter, 2005). Accumulating evidence indicates that $\mathrm{H}_{2} \mathrm{~S}$ functions in various processes in plants, including seed germination, root organogenesis, abiotic stress tolerance, photosynthesis, guard cell movement, and postharvest senescence, suggesting that $\mathrm{H}_{2} \mathrm{~S}$ acts as an important gaseous regulator in plants, as do NO and CO (Chen et al., 2011; García-Mata and Lamattina, 2010; Zhang et al., 2008, 2009, 2011).

In recent years, there has been a rapid expansion in the sale of fresh-cut apples due to the advantages offered by ready-to-eat or ready-to-use fresh produce (Rico et al., 2007). However, exposure of cut surfaces of fruits to external factors makes these products perishable with a shorter shelf life than intact fruits. Fresh-cut processing operations destroy many layers of fruit tissue and trigger wounding and tissue deterioration. Increased respiration, accelerated ripening and senescence, accompanied by excessive consumption of sugars, lipids and higher ethylene production are found in fresh-cut products (Kays, 1991).

It has been generally accepted that postharvest fruits undergo programmed senescence accompanied by various physiological and biochemical changes, including oxidative damage caused by reactive oxygen species (ROS) such as superoxide radicals $\left(\cdot \mathrm{O}_{2}^{-}\right)$and $\mathrm{H}_{2} \mathrm{O}_{2}$ (Raseetha et al., 2013). ROS is highly reactive and causes lipid peroxidation, which could lead to undesirable flavors and odors due to increased LOX activity and malondialdehyde (MDA) content in fruit tissues (Hu et al., 2014). Nonenzymatic compounds and antioxidant enzymes have been used to degrade excess ROS to mitigate oxidative damage in strawberry (Mittler et al., 2004).

Ethylene is a major regulator of fruit ripening and senescence, and can induce softening in apples by regulating the expression of cell wall-modifying enzymes (Johnston et al., 2002). 1-Aminocyclopropane1-carboxylic acid (ACC) synthase (ACS) and ACC oxidase (ACO) are key enzymes for ethylene production, which catalyze the conversion of S-adenosyl methionine to ACC and ACC to ethylene, respectively (Lin et al., 2009). Li et al. (2015) showed that the postharvest application of $\mathrm{H}_{2} \mathrm{~S}$ alleviated darkpromoted senescence by reducing the transcripts of $B o A C S 2$ and $B o A C S 3$ in broccoli. Pristijono et al. (2006) indicated that NO delayed ripening and senescence of apple slices by influencing ethylene production during postharvest storage. However, there are few reports on the effects of $\mathrm{H}_{2} \mathrm{~S}$ on the ethylene signaling pathway and on the antioxidant system and enzymatic browning of fresh-cut fruits. Thus, we hypothesize that $\mathrm{H}_{2} \mathrm{~S}$ has similar positive effects as $\mathrm{NO}$ in delaying postharvest senescence of apple slices. We therefore studied the roles of $\mathrm{H}_{2} \mathrm{~S}$ in detoxifying ROS overproduction, enhancing antioxidant defense, and regulating the expression of senescence-related genes in apple slices.

\section{Materials and Methods}

Plant materials and treatment. 'Fuji' apple (Malus xpumila) used in this work was supplied by Anhui Academy of Agricultural Sciences, Hefei, Anhui Province, China. Unwounded, healthy fruits of uniform size, color, and weight were selected for experiments. Apples were washed with tap water and sterilized with $75 \%$ ethanol. In sealed 3-L containers, $200 \mathrm{~mL}$ sodium hydrosulfide (NaHS) solutions at concentrations of 0.0 , $0.2,0.4,0.6,0.8$, and $1.0 \mathrm{mmol} \cdot \mathrm{L}^{-1}$ were prepared. Each apple was hand cut longitudinally into six unpeeled slices using a sharp stainless steel knife, and six cut pieces from six different apples were exposed to $\mathrm{H}_{2} \mathrm{~S}$ gas released from NaHS solution in the sealed containers for $0-5 \mathrm{~d}$. Storage temperature was $25 \pm 0.5^{\circ} \mathrm{C}$ and relative humidity ranged from $85 \%$ to $90 \%$. NaHS solutions were renewed daily, and the apples were observed every $24 \mathrm{~h}$. After treatment, apple slices were 
peeled, cored, and stored at $-80{ }^{\circ} \mathrm{C}$ for further analysis.

Assessment of rot index and external color of apple slices. Rot index was recorded using the method described by Cao et al. (2010) with minor modifications. Six apple slices were selected for rot index in each treatment. All slices were classified in five ranks according to the percentage of rotten surface area: 0 , no rot; 1 , rot surface less than $10 \% ; 2$, rot surface between $10 \%$ and $30 \% ; 3$, rot surface between $30 \%$ and $50 \%$; 4 , rot surface more than $50 \%$. The rot index was calculated and recorded every $2 \mathrm{~d}$ using the following formula: rot index $=\left[\sum A B / 6\right]$, where $A$ represents the rot rank of individual slice, $B$ the number of slice at that rot rank.

External color of cut surface of apple slices (a total of 12 cut surfaces of 6 apple slices for each treatment) was directly measured with a color difference meter (model WSC-100; Konica Minolta, Tokyo, Japan), providing CIE (Commission Internationale de l'Éclairage) $\mathrm{L}^{*}, \mathrm{a}^{*}$, and $\mathrm{b}^{*}$ values. $\mathrm{L}^{*}$ stands for lightness, $\mathrm{a}^{*}$ shows chromaticity on a green $(-)$ to red $(+)$ axis, and $b^{*}$ chromaticity on a blue (-) to yellow ( + ) axis (Gil et al., 1997). These values were then used to calculate hue angle $\left(\mathrm{H}^{\circ}\right)$, where $0^{\circ}=$ red-purple; $90^{\circ}=$ yellow; $180^{\circ}=$ bluish green; and $270^{\circ}=$ blue and chroma $\left(\mathrm{C}^{*}\right)$, which indicates the intensity or color saturation (McGuire, 1992).

Determination of reducing sugar, soluble protein, and free amino acid in apple slices. Soluble protein and reducing sugar contents were measured according to Bradford (1976) and Miller (1959), respectively. Fruit samples $(5.00 \pm 0.05 \mathrm{~g})$ were ground in $5 \mathrm{~mL}$ of phosphate buffer $\left(\mathrm{pH} 7.0,200 \mathrm{mmol} \cdot \mathrm{L}^{-1}\right)$. The homogenate was centrifuged at 10,000 $g_{\mathrm{n}}$ for $30 \mathrm{~min}$, and the supernatant was used for determination of soluble protein and reducing sugar content. For soluble protein, $0.1 \mathrm{~mL}$ of supernatant was mixed with $0.9 \mathrm{~mL}$ of $\mathrm{dH}_{2} \mathrm{O}$ and $5 \mathrm{~mL}$ of Coomassie brilliant blue. Absorbance was recorded at $595 \mathrm{~nm}$ after $5 \mathrm{~min}$. The results were expressed on a fresh weight (FW) basis as $\mathrm{mg} \cdot \mathrm{g}^{-1}$.

Reducing sugar was measured via the dinitrosalicylic acid method. The supernatant $(0.2 \mathrm{~mL})$ was mixed with $1.5 \mathrm{~mL}$ of $3,5-$ dinitrosalicylic acid and $1.8 \mathrm{~mL}$ of $\mathrm{dH}_{2} \mathrm{O}$, then the mixture was heated at $100{ }^{\circ} \mathrm{C}$ for $5 \mathrm{~min}$, cooled, and added to $25 \mathrm{~mL}$ distilled water. Reducing sugar was determined at $540 \mathrm{~nm}$ by using a spectrophotometer, and the results were expressed on an FW basis as $\mathrm{mg} \cdot \mathrm{g}^{-1}$.

For determination of amino acid, $5.00 \pm$ $0.05 \mathrm{~g}$ apple tissues were ground in $5 \mathrm{~mL}$ ethanol. The homogenate was centrifuged at $10,000 g_{\mathrm{n}}$ for $10 \mathrm{~min}$ and the supernatant was heated at $80{ }^{\circ} \mathrm{C}$ to remove ethanol. The residue was then suspended in $\mathrm{dH}_{2} \mathrm{O}$ and filtered through a membrane $(0.45-\mu \mathrm{m}$ pore width) and used for free amino acid assay with a Beckman Coulter S433D amino acid analyzer (Brea, CA) (Simpson et al., 1976).

Analysis of ascorbic acid, total phenolics, and flavonoid in apple slices. Ascorbic acid content was determined using the 2,6-dichloroindophenol titrimetric method according to the Association of Official Analytical Chemists (AOAC, 1984). Determination of total phenolics and flavonoids in apple slices were performed according to the methods of Pirie and Mullins (1976) and Jia et al. (1999), respectively.

Determinations of $\cdot \mathrm{O}_{2}^{-}, \mathrm{H}_{2} \mathrm{O}_{2}$, and $\mathrm{MDA}$ content in apple slices. Contents of $\cdot \mathrm{O}_{2}^{-}$, $\mathrm{H}_{2} \mathrm{O}_{2}$, and MDA were determined according to the methods described by $\mathrm{Hu}$ et al. (2013) and Zhang et al. (2011) with minor modifications. Of the extract obtained from the method for SOD extraction, $0.5 \mathrm{~mL}$ was mixed with $0.5 \mathrm{~mL}$ of $50 \mathrm{mmol} \cdot \mathrm{L}^{-1}$ potassium phosphate buffer ( $\mathrm{pH} 7.5$ ) and $0.1 \mathrm{~mL}$ of $1 \mathrm{mmol} \cdot \mathrm{L}^{-1}$ hydroxyl ammonium chloride, and then incubated for $30 \mathrm{~min}$ at $30^{\circ} \mathrm{C}$. This solution was added to $1 \mathrm{~mL}$ of $17 \mathrm{mmol} \cdot \mathrm{L}^{-1}$ 3 -aminobenzenesulphonic acid and $1 \mathrm{~mL}$ of 7 $\mathrm{mmol} \cdot \mathrm{L}^{-1}$ 1-naphthylamine, incubated for a further $20 \mathrm{~min}$ at $30^{\circ} \mathrm{C}$ and centrifuged at $8000 g_{n}$ for $5 \mathrm{~min}$. Absorbance of the solution was monitored at $530 \mathrm{~nm}$. The rate of $\bullet \mathrm{O}_{2}$ production was expressed on an $\mathrm{FW}$ basis as $\mu \mathrm{g} \cdot \mathrm{g}^{-1} \cdot \mathrm{s}^{-1}$.

For determination of $\mathrm{H}_{2} \mathrm{O}_{2}$, fruit samples $(5.00 \pm 0.05 \mathrm{~g})$ were ground and extracted in $3 \mathrm{~mL}$ cold acetone. The homogenate was centrifuged at $10,000 g_{\mathrm{n}}$ at $4{ }^{\circ} \mathrm{C}$ for $30 \mathrm{~min}$, and $0.5 \mathrm{~mL}$ of the supernatant fraction was mixed with $1.5 \mathrm{~mL}$ of $\mathrm{CHCl}_{3}$ and $\mathrm{CCl}_{4}(1: 3$, $\mathrm{v} / \mathrm{v})$ mixture, then $2.5 \mathrm{~mL}$ of $\mathrm{dH}_{2} \mathrm{O}$ was added, and the mixture was centrifuged at $10,000 g_{\mathrm{n}}$ for $1 \mathrm{~min}$ and the aqueous phase was collected for $\mathrm{H}_{2} \mathrm{O}_{2}$ determination. The reaction system included $0.5 \mathrm{~mL}$ sample, $0.5 \mathrm{~mL}$ of buffer (phosphate-buffered saline, $\left.200 \mathrm{mmol} \cdot \mathrm{L}^{-1}, \mathrm{pH} 7.8\right)$, and $20 \mu \mathrm{L}$ (0.5 unit) of CAT (as controls) or inactive CAT protein (CAT inactivated by heating in boiling water for $5 \mathrm{~min}$ ). After the mixture was incubated at $37{ }^{\circ} \mathrm{C}$ for $10 \mathrm{~min}, 0.5 \mathrm{~mL}$ of $200 \mathrm{mmol} \cdot \mathrm{L}^{-1}$ titanium 4-(2-pyridylazo)resorcinol was added. The reaction mixture was incubated at $45{ }^{\circ} \mathrm{C}$ for another $20 \mathrm{~min}$. Absorbance at $508 \mathrm{~nm}$ was measured. $\mathrm{H}_{2} \mathrm{O}_{2}$ content was indicated on an FW basis as $\mu \mathrm{mol} \cdot \mathrm{g}^{-1}$.

For MDA analysis, fruit samples $(5.00 \pm$ $0.05 \mathrm{~g}$ ) were ground in $3 \mathrm{~mL}$ of $0.1 \%$ trichloroacetic acid (TCA) and centrifuged at $10,000 \mathrm{~g}_{\mathrm{n}}$ for $30 \mathrm{~min}$, and $1.8 \mathrm{~mL}$ of the supernatant fraction was mixed with $1.8 \mathrm{~mL}$ of $20 \%$ TCA containing $0.5 \%$ thiobarbituric acid. The mixture was heated at $100{ }^{\circ} \mathrm{C}$ for 30 $\mathrm{min}$, cooled, and centrifuged at $15,000 \mathrm{~g}_{\mathrm{n}}$ for $10 \mathrm{~min}$. Absorbance was recorded at $532 \mathrm{~nm}$, and the value for nonspecific absorption at $600 \mathrm{~nm}$ was subtracted. An extinction coefficient of $155 \mathrm{~mm}^{-1} \cdot \mathrm{cm}^{-1}$ was used to calculate MDA content, and the content of MDA in apple was indicated on an FW basis as $\mu \mathrm{mol} \cdot \mathrm{g}^{-1}$.

Activity assays of APX, CAT, GR, LOX, $P A L, P O D, P P O, S O D$, and protease in apple slices. APX (EC 1.11.1.11), CAT (EC 1.11.1.6), POD (EC 1.11.1.7), and SOD (EC 1.15.1.1) were assayed according to the method by Garcia-Limones et al. (2002). Apple tissues $(5.00 \pm 0.05 \mathrm{~g})$ were homogenized in $3.0 \mathrm{~mL}$ ice-cold $50 \mathrm{mmol} \cdot \mathrm{L}^{-1}$ potassium phosphate buffer $(\mathrm{pH}$ 7.5) containing
$1.0 \mathrm{mmol} \cdot \mathrm{L}^{-1}$ ethylenediaminetetraacetic acid (EDTA), $1.0 \mathrm{mmol} \cdot \mathrm{L}^{-1}$ phenylmethanesulfonyl fluoride (PMSF), $5 \mathrm{mmol} \cdot \mathrm{L}^{-1}$ sodium ascorbate, and $5 \%(\mathrm{w} / \mathrm{v})$ polyvinyl pyrrolidone, centrifuged at $10,000 g_{n}$ at $4{ }^{\circ} \mathrm{C}$ for $30 \mathrm{~min}$, and the supernatant was divided into aliquots, frozen in liquid nitrogen, and stored at $-80{ }^{\circ} \mathrm{C}$ for further activity measurement. APX activity was determined in the presence of $2.0 \mathrm{mmol} \cdot \mathrm{L}^{-1}$ ascorbic acid and $2.0 \mathrm{mmol} \cdot \mathrm{L}^{-1}$ EDTA by measuring the decrease in absorbance at $290 \mathrm{~nm}$. For CAT activity, $\mathrm{H}_{2} \mathrm{O}_{2}$ was used as substrate. CAT activity was assayed spectrophotometrically by monitoring the decrease in absorbance at $240 \mathrm{~nm}$. Analysis of POD activity was based on the oxidation of guaiacol using $\mathrm{H}_{2} \mathrm{O}_{2}$ by monitoring an increase in absorbance at $470 \mathrm{~nm}$. One unit of APX, CAT, and POD was defined as an increase or decrease of 0.01 in absorbance per minute under the assay conditions. The activities of APX, CAT, and POD were expressed on an FW basis as U.g ${ }^{-1}$. SOD activity was assayed from the inhibition of the photochemical reduction of nitroblue tetrazolium (NBT) in the presence of riboflavin. One SOD unit was defined as the amount of enzyme that inhibits the rate of NBT reduction by $50 \%$ under the above assay conditions. The activity was expressed on an FW basis as $\mathrm{U} \cdot \mathrm{g}^{-1}$.

Activities of GR (EC 1.6.4.2) and LOX (EC 1.13.11.12) were detected by procedures described by Garcia-Limones et al. (2002) and Surrey (1964), respectively. One unit of GR and LOX was defined as a decrease of $0.01 \mathrm{OD}$ value in absorbance per minute, and the results were expressed on an FW basis as $\mathrm{U} \cdot \mathrm{g}^{-1}$.

Activity of PAL (EC 4.3.1.5) was determined by the procedures described by Beaudoin-Eagan and Thorpe (1985). One unit of PAL activity was defined as a change of $0.01 \mathrm{OD}$ value in absorbance at $290 \mathrm{~nm}$ per minute. The results were expressed on an FW basis as U.g ${ }^{-1}$. Activity of PPO (EC 1.10.3.1) was assayed according to the method by Benjamin and Montgomery (1973). Apple samples $(5.00 \pm 0.05 \mathrm{~g})$ were homogenized with $3.0 \mathrm{~mL}$ of sodium phosphate buffer (50 mmol. $\mathrm{L}^{-1}, \mathrm{pH}$ 6.8). After centrifugation, the supernatant was used for the activity assay using catechol as substrate. One unit of PPO activity was defined as an increase of $0.01 \mathrm{OD}$ value in absorbance at $410 \mathrm{~nm}$ per minute. The results were expressed on an FW basis as $\mathrm{U} \cdot \mathrm{g}^{-1}$

The method described previously by Reimerdes and Klostermeyer (1976) was adopted to determine protease activity. One unit of protease activity was defined as an increase of $0.1 \mathrm{OD}$ value in absorbance at $278 \mathrm{~nm}$ per hour. The results were expressed on an $\mathrm{FW}$ basis as $\mathrm{U} \cdot \mathrm{g}^{-1}$.

$R N A$ extraction and reversed transcript polymerase chain reaction. Fresh-cut apple samples were ground to powder in liquid nitrogen, and RNA was extracted by the RNAiso for Polysaccharide-rich Plant Tissue (Takara, Kyoto, Japan) according to the manufacturer's instructions. First-strand cDNA was synthesized using a reverse 
transcription kit (Prime Script ${ }^{\mathrm{TM}}$ RT Master Mix; Takara) from $2.5 \mu \mathrm{g}$ total RNA. cDNA fragments were amplified by reversed transcript polymerase chain reaction (RT-PCR) with Easy Taq ${ }^{\mathrm{TM}}$ DNA Polymerase (TransGen, Beijing, China). Primers used for RTPCR are shown in Table 1. PCR conditions were initial denaturation at $94{ }^{\circ} \mathrm{C}$ for $5 \mathrm{~min}$, followed by appropriate cycles of $94{ }^{\circ} \mathrm{C}$ for $30 \mathrm{~s}, 52{ }^{\circ} \mathrm{C}$ for $30 \mathrm{~s}$, and $72{ }^{\circ} \mathrm{C}$ for $30 \mathrm{~s}$. Md18sRNA was used as a control.

Statistical analysis. The data in the manuscript are based on three replicates in each experiment, and the experiments were repeated independently for three times and similar change pattern was observed. Statistical significance was tested by one-way analysis of variance (ANOVA) using IBM SPSS Statistics (SPSS version 20.0; Armonk, $\mathrm{NY}$ ), and the results were expressed as the means \pm SD. Least significant difference test was performed on all data following ANOVA tests to test for significant $(P<0.05$ or $P<$ $0.01)$ differences between treatments.

\section{Results}

$\mathrm{H}_{2} \mathrm{~S}$ alleviates postharvest senescence of apple slices. Fresh-cut apple slices were fumigated with $\mathrm{H}_{2} \mathrm{~S}$ released from different concentrations of aqueous solutions of NaHS with slices exposed to water as controls. The positive effect of $\mathrm{H}_{2} \mathrm{~S}$ on delaying senescence of apple slices is presented in Fig. 1A. Rot index of water control apple slices increased quickly after $2 \mathrm{~d}$ of storage and reached a maximum value on Day 6, while different NaHS treatments alleviated postharvest rot in a dose-dependent manner (Fig. 1B). However, there was no additional protection against browning, senescence, and rot after exposure to concentrations of NaHS above $0.4 \mathrm{mmol} \cdot \mathrm{L}^{-1}$. Thus, $0.4 \mathrm{mmol} \cdot \mathrm{L}^{-1} \mathrm{NaHS}$ was regarded as optimal and was the concentration used in all subsequent experiments. The change in external color of cut surfaces was evaluated, and the results showed the decrease in lightness and hue angle values in control fruits (Fig. 2A and $\mathrm{C}$ ), while $\mathrm{H}_{2} \mathrm{~S}$ treatment significantly delayed the darkening and browning of fruit slices compared with those of controls. Besides, chroma of control slices increased significantly with the storage time, while the increase was attenuated in $\mathrm{H}_{2} \mathrm{~S}$-fumigated fruit (Fig. 2B).

Effects of $\mathrm{H}_{2} \mathrm{~S}$ on the contents of reducing sugars, soluble protein, free amino acids, ascorbic acid, total phenolics, and flavonoids in apple slices. As shown in Fig. 3A, reducing sugar content in water controls accumulated slightly to a maximum on Day 3, and then declined, whereas the content of reducing sugars in $\mathrm{H}_{2} \mathrm{~S}$-fumigated fruit increased gradually to Day 3 of storage then plateaued (Fig. 3A). Soluble protein content of apple slices continually decreased during storage in water controls, but the content significantly increased in $\mathrm{H}_{2} \mathrm{~S}$ treated apple slices in the first $2 \mathrm{~d}$ of storage (Fig. 3B).
Ascorbic acid content in apple slices declined steadily regardless of treatments (Fig. 3C). However, apple slices in $0.4 \mathrm{mmol} \cdot \mathrm{L}^{-1} \mathrm{NaHS}$ treatment sustained significantly higher levels of ascorbic acid compared with water controls after $2 \mathrm{~d}$ of storage (Fig. 3C). Results in Fig. 3D show that $\mathrm{H}_{2} \mathrm{~S}$ application induced an accumulation of total phenolics, whereas they were significantly lower in controls during the whole storage period (Fig. 3D). Similarly, Fig. 3E shows that apple slices exposure to $\mathrm{H}_{2} \mathrm{~S}$ contained significantly higher level of flavonoids in comparison with controls.
Table 2 illustrates the changes in selected amino acids and total amino acids in control and NaHS-treated apple slices during $3 \mathrm{~d}$ of incubation. $\mathrm{H}_{2} \mathrm{~S}$ application sustained significantly lower levels of total free amino acids, dropping by $\approx 33 \%$ relative to water control after $3 \mathrm{~d}$ of storage. Both cysteine (Cys) and histidine (His) content in $\mathrm{H}_{2} \mathrm{~S}$-treated tissue were higher than those of water control. His content increased significantly on Day 3 in both control and NaHS treatment compared with those on Day 0. An increase in alanine (Ala), aspartic acid (Asp), glutamic acid (Glu), and serine (Ser) was observed in water controls on Day 3 relative to Day 0, and the

Table 1. Primers used for reversed transcript polymerase chain reaction amplification of senescencerelated gene expression.

\begin{tabular}{lll}
\hline Gene name & \multicolumn{1}{c}{ Forward primer $\left(5^{\prime}-3^{\prime}\right)$} & \multicolumn{1}{c}{ Reverse primer $\left(5^{\prime}-3^{\prime}\right)$} \\
\hline$M d D H A R$ & ATCAATCTCAGCGACAAACC & ACAATCACATCGGAATCAGG \\
$M d P A L$ & GAGGAACACCGTAAAGAACA & AAACATACTCCCTATCGACAAC \\
$M d P P O$ & CGTCATCAGGGAAGGTGG & ACTCGCTCTTGTCGGGTC \\
$M d L O X 2$ & TCAAACCGCCCAACCCTA & GCCTCAATCGCTTCCAAA \\
$M d P G 1$ & TCCTTCGTGACCCTCCTTTT & TCAGCACCATTCCCTTTAGC \\
$M d A C S 1$ & GGGCACCACAATGACCAGA & CCAACAGAACAAGCCAGCA \\
$M d A C S 3$ & AGCAACCCATCTGGAGTCATAC & TTTGGCTCTTCCTCCTCTAATT \\
$M d A C O 1$ & TCAAGGATGGTGAATGGGTG & AATGAGTCGTTGCCTGGGTT \\
$M d A C O 2$ & GACGGAGAGTGGGTTGATGT & TAGGGTTGGTGCTGGGTAGA \\
$M d E T R 1$ & CTTATTTCTCCATCCCGCTA & CCAATGCCAAAGTTCTACCT \\
$M d E R S 1$ & TGCCTATTTCTCCATTCCCTT & TCAGCATCCTAACATGCCTTC \\
$M d E R S 2$ & CTGTCTTTCGCCCTCCACT & TTCACCAGCAACTCATCCG \\
$M d E R F 3$ & GAGGAAGAGAAGATACAGGGGA & GAAGGTTTGGAGAGTTGGTGGT \\
$M d E R F 4$ & CACTCCCTCCAAACCCACAA & GCGAGCAAAGTCTCCCCTAA \\
$M d E R F 5$ & AAGTGGGTGGCGGAGATTC & ATGAGCGGAGAGCGGTTTG \\
$M d 18 S R N A$ & CTGCCCGTTGCTCTGATG & CTGCCTTCCTTGGATGTGGT \\
\hline
\end{tabular}

A

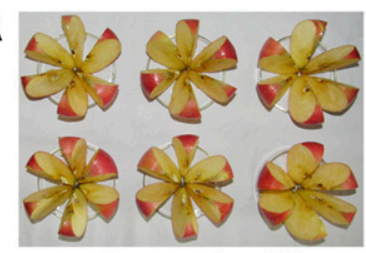
storage for Od

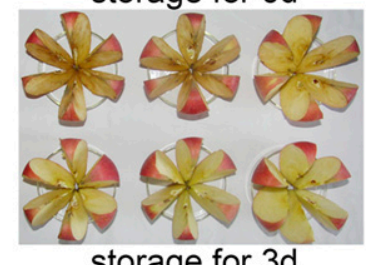

B

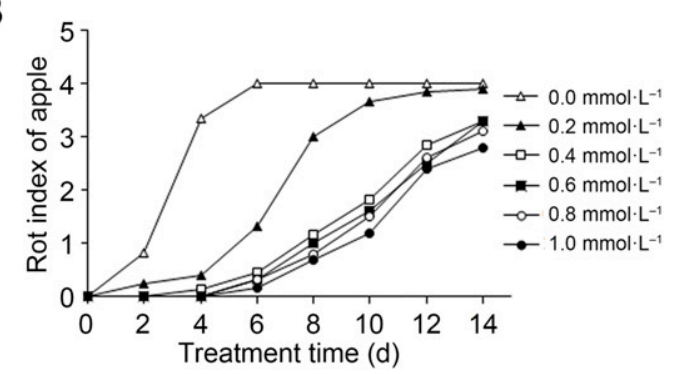

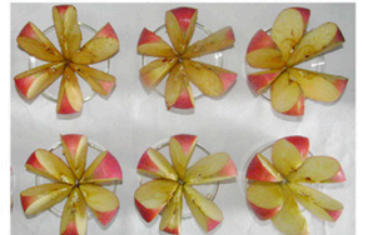

storage for $2 \mathrm{~d}$

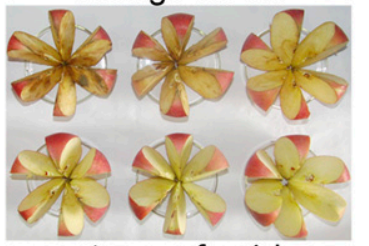

storage for $4 d$

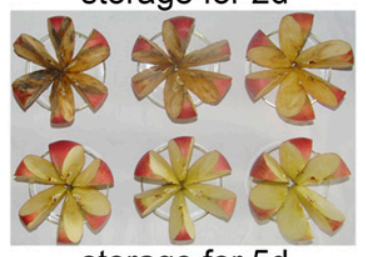

storage for $5 d$

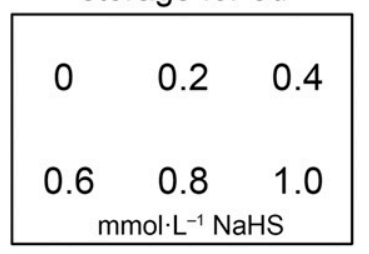

Fig. 1. Effects of hydrogen sulfide $\left(\mathrm{H}_{2} \mathrm{~S}\right)$ on $(\mathbf{A})$ postharvest shelf life and $(\mathbf{B})$ rot index of fresh-cut apples. Fresh-cut apples were respectively fumigated with different concentrations $(0,0.2,0.4,0.6,0.8$, and $\left.1.0 \mathrm{mmol} \cdot \mathrm{L}^{-1}\right)$ of aqueous solutions of sodium hydrosulfide (NaHS) for 0-14 $\mathrm{d}$ as shown in lower right part of A. Photographs (A) were taken from Day 0 to Day 5, and the rot index (B) of apple slices was recorded every $2 \mathrm{~d}$ from Day 0 to Day 14. 
contents of Ala, Asp, Glu, and Ser in NaHS treatment were lower than those of control on Day 3. Cys and Valine were detected only in untreated and treated samples on Day 3, respectively, while other amino acids were not detectable (Table 2).

$\mathrm{H}_{2} \mathrm{~S}$ decreases the production rate of $-\mathrm{O}_{2}^{-}$and the contents of $\mathrm{H}_{2} \mathrm{O}_{2}$ and MDA. The production rate of $\bullet^{\mathrm{O}_{2}}{ }^{-}$and the contents of $\mathrm{H}_{2} \mathrm{O}_{2}$ and MDA in $\mathrm{H}_{2} \mathrm{~S}$-fumigated fruits and controls are shown in Fig. 4. The generation of $\cdot \mathrm{O}_{2}{ }^{-}$in control apple slices increased steadily over $5 \mathrm{~d}$, whereas $\mathrm{H}_{2} \mathrm{~S}$ fumigation significantly inhibited $\cdot \mathrm{O}_{2}$ production rate (Fig. 4A). As shown in Fig. $4 \mathrm{~B}, \mathrm{H}_{2} \mathrm{O}_{2}$ content increased both in control and NaHS-treated apple slices during the whole storage period. However, a lower level of $\mathrm{H}_{2} \mathrm{O}_{2}$ was maintained by $\mathrm{H}_{2} \mathrm{~S}$ in comparison with controls (Fig. 4B). MDA content showed a quick increase during the entire storage in control apple slices, whereas the content in $\mathrm{H}_{2} \mathrm{~S}$-treated apple was maintained at a significantly lower level (Fig. 4C).
$\mathrm{H}_{2} \mathrm{~S}$ upregulates the activities of $A P X$, CAT, GR, POD, SOD and downregulates the activities of $L O X, P A L, P P O$, and protease in apple slices. To further understand the role of $\mathrm{H}_{2} \mathrm{~S}$ in ROS metabolism in apple slices, we measured the activities of enzymes involved in oxidative metabolism in plants, such as APX, CAT, GR, LOX, PAL, PPO, POD, and SOD in apple slices exposed to $0.4 \mathrm{mmol} \cdot \mathrm{L}^{-1} \mathrm{NaHS}$ or water (Fig. 5). As shown in Fig. $5 \mathrm{~A}, \mathrm{H}_{2} \mathrm{~S}$ fumigation induced a rapid increase of CAT activity until $2 \mathrm{~d}$ followed by a decline on Day 3. In contrast, CAT activity in water control decreased immediately on $1 \mathrm{~d}$ of storage then slightly increased on Day 2 followed by a relative lower level compared with $\mathrm{H}_{2} \mathrm{~S}$ treatment. Figure 5B shows that APX activities increased in both control and NaHS treatment during $5 \mathrm{~d}$ of incubation. $\mathrm{H}_{2} \mathrm{~S}$ fumigation induced a burst of APX activity on $1 \mathrm{~d}$, and its activity was maintained at a significantly higher level compared with water control (Fig. 5B). Figure 5C illustrates a similar pattern of POD activity in both water and
NaHS treatments. POD activity increased steadily in both treatments, whereas significantly higher activities were observed in fruits exposed to $\mathrm{H}_{2} \mathrm{~S}$ compared with controls (Fig. 5C). As shown in Fig. 5D, $\mathrm{H}_{2} \mathrm{~S}$ fumigation maintained significantly higher SOD activity compared with controls during the entire storage. SOD activity increased gradually in $\mathrm{H}_{2} \mathrm{~S}$-treated apple until $4 \mathrm{~d}$, thereafter it was maintained at a constant level, while SOD activity in control slices increased and peaked on Day 2 followed by a decline (Fig. 5D). Figure 5E shows that GR activities were enhanced in NaHS treatment in comparison with water control. GR activities in $\mathrm{H}_{2} \mathrm{~S}$-treated fruits increased steadily, while in water control increased after $2 \mathrm{~d}$ of storage and peaked on Day 4 (Fig. 5E).

Figure $5 \mathrm{~F}$ shows the changes in the activity of LOX, an index of lipid peroxidation, in apple slices. In water controls, LOX activity was induced on the first day of storage and then declined on Day 2 followed by a steady increase. In contrast, LOX activity was maintained at a lower level in
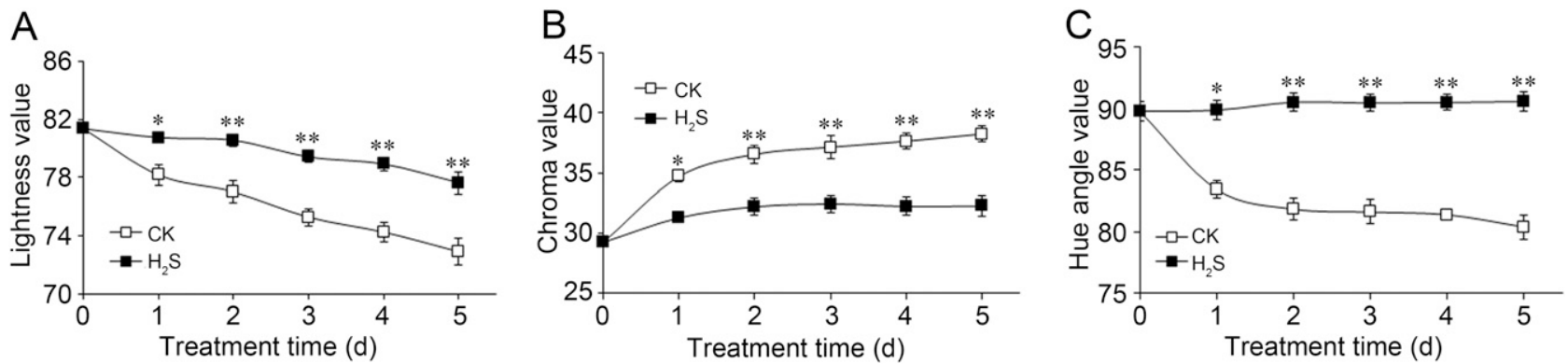

Fig. 2. Effects of hydrogen sulfide $\left(\mathrm{H}_{2} \mathrm{~S}\right)$ on change of $(\mathbf{A})$ lightness, $(\mathbf{B})$ chroma, and $(\mathbf{C})$ hue angle value of fresh-cut apple slices during storage at $25^{\circ} \mathrm{C}$. Apple slices were fumigated with $0.4 \mathrm{mmol} \cdot \mathrm{L}^{-1} \mathrm{H}_{2} \mathrm{~S}$ donor sodium hydrosulfide aqueous solution $\left(\mathrm{H}_{2} \mathrm{~S}\right)$ with water as the control groups $(\mathrm{CK})$ for $0-5 \mathrm{~d}$. Data are presented as means $\pm \mathrm{SD}(\mathrm{n}=12)$. The symbols * and ** in this figure and following ones stand for significant difference between $\mathrm{CK}$ and $\mathrm{H}_{2} \mathrm{~S}$ at $P<0.05$ and $P<0.01$, respectively.
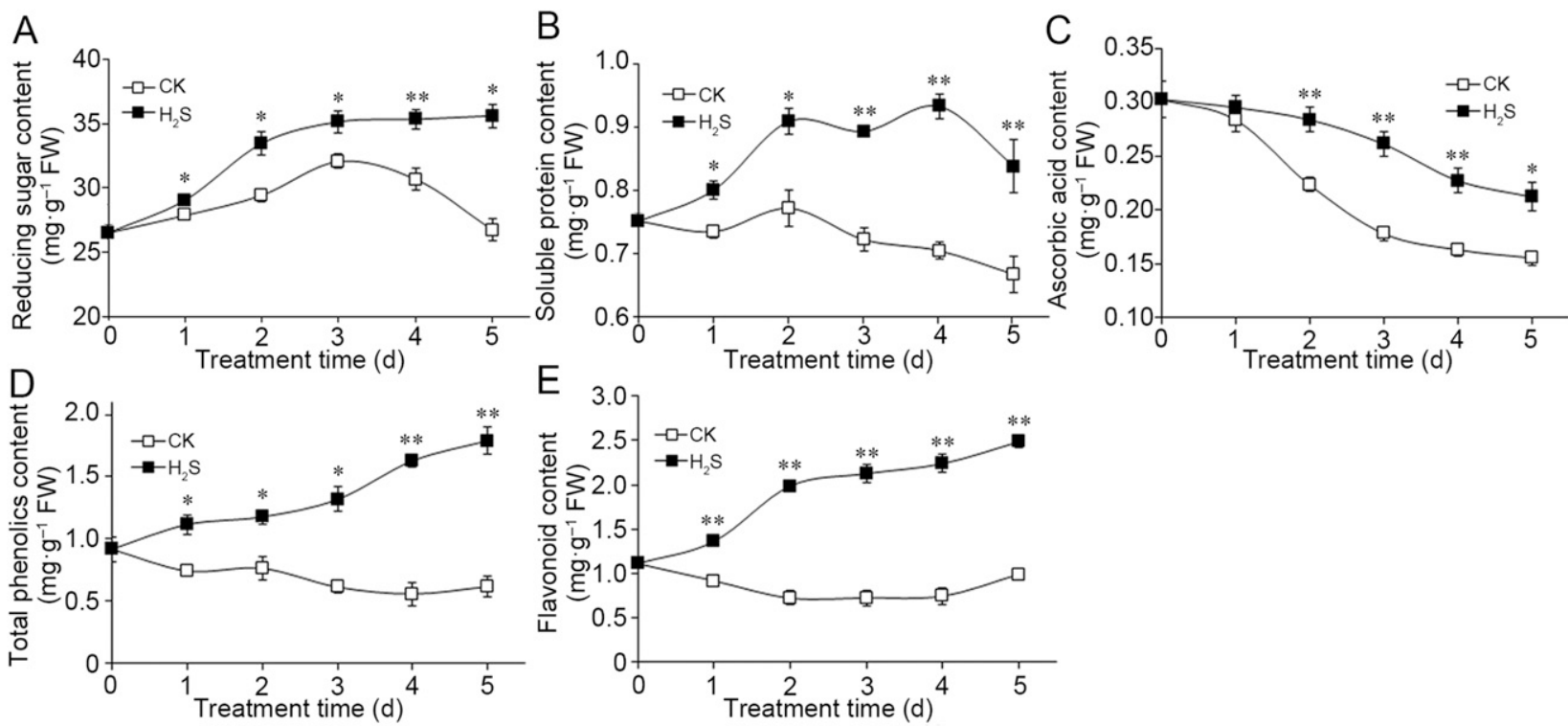

Fig. 3. Effects of hydrogen sulfide $\left(\mathrm{H}_{2} \mathrm{~S}\right)$ on the contents of $(\mathbf{A})$ reducing sugar, $(\mathbf{B})$ soluble protein, $(\mathbf{C})$ ascorbic acid, (D) total phenolics, and $(\mathbf{E})$ flavonoid in apple slices. Apple slices were fumigated with $0.4 \mathrm{mmol} \cdot \mathrm{L}^{-1} \mathrm{H}_{2} \mathrm{~S}$ donor sodium hydrosulfide aqueous solution $\left(\mathrm{H}_{2} \mathrm{~S}\right)$ with water as the control groups $(\mathrm{CK})$ for $0-5$ d. Data are presented as means $\pm \mathrm{SD}(\mathrm{n}=3)$. $\mathrm{FW}=$ fresh weight. 
$\mathrm{H}_{2} \mathrm{~S}$-treated tissue than in water controls (Fig. 5F). As shown in Fig. 5G, NaHS treatment maintained lower activities of PPO compared with control. PPO activity in control apples increased rapidly and was about 1.4-fold higher than $\mathrm{H}_{2} \mathrm{~S}$-treated fruit on $1 \mathrm{~d}$, then declined till Day 3 followed by a relatively stable level, whereas PPO activity in NaHS treatment was maintained at a significantly lower level in comparison with control (Fig. 5G). Figure 5H illustrates similar patterns in PAL activities both in $\mathrm{H}_{2} \mathrm{~S}$ treatments and water controls. In both treatments, PAL activities declined immediately and were lowest on Day 2 of storage, then increased more on Day 3 followed by a slight decrease until the end of storage. However, $\mathrm{H}_{2} \mathrm{~S}$ application maintained significantly lower levels of PAL activities relative to controls except the first day of storage (Fig. 5H).

The changes in protease activities were shown in Fig. 5I. Consistent with the higher level of soluble protein and lower level of total free amino acids in $\mathrm{H}_{2} \mathrm{~S}$-fumigated fruits (Fig. 3B; Table 2), $\mathrm{H}_{2} \mathrm{~S}$ fumigation significantly inhibited the enhancement of protease activity compared with that of controls since the second day of storage.

Effect of $\mathrm{H}_{2} \mathrm{~S}$ on the relative expressions of senescence-related genes. Figure 6A shows the effects of $\mathrm{H}_{2} \mathrm{~S}$ on the relative expression of $M d D H A R$ (dehydroascorbate reductase), $M d L O X 2, M d P A L, M d P P O$, and $M d P G 1$ (polygalacturonase). After fresh-cut processing, MdDHAR expression in apple slice declined on Day 2 of storage, while $\mathrm{H}_{2} \mathrm{~S}$ treatment significantly enhanced the $M d D H A R$ expression. On the contrary, $\mathrm{H}_{2} \mathrm{~S}$ significantly suppressed $M d L O X 2$ expression on Day 2 compared with water control. The expressions of $M d P A L, M d P P O$, and $M d P G 1$ were induced after $1 \mathrm{~d}$ of storage in water control, suggesting that these genes were expressed along with storage. However, $\mathrm{H}_{2} \mathrm{~S}$-fumigated apple contained lower expression levels of these genes on Day 1 $(M d P A L, M d P P O)$ or Day $2(M d P G l)$ of storage in comparison with controls (Fig. 6A).

We also studied the effects of $\mathrm{H}_{2} \mathrm{~S}$ on ethylene biosynthesis genes (MdACS1, $M d A C S 3, M d A C O 1$, and $M d A C O 2)$ and signal transduction genes (MdETR1, MdERS1, MdERS2, MdERF3, MdERF4, and MdERF5) by RT-PCR analysis. Figure $6 \mathrm{~B}$ shows that the expressions of MdACS1 (1aminocyclopropane-1-carboxylic acid synthase 1), MdETR1 (ethylene receptor 1), MdERS1 (ethylene response sensor 1), and $M d E R F 3$ (ethylene-responsive factor 3) decreased slightly on Day 1 then increased on Day 2 in control samples, while $\mathrm{H}_{2} \mathrm{~S}$ fumigation inhibited the expressions of $\mathrm{MdACO1}$ (1-aminocyclopropane-1-carboxylate oxidase 1), MdETR1, and MdERSI (on Day 2) and induced the expression of MdERF3 and MdERF5. However, $\mathrm{H}_{2} \mathrm{~S}$ had no significant influence on the expressions of MdACS1 and MdERF4 compared with water controls. The expression of $M d A C S 3, M d A C O 2$, and MdERS2 were not detectable regardless of treatments (Fig. 6B).

\section{Discussion}

In the present study, fresh-cut apple slices were used as a model to study the physiological function of $\mathrm{H}_{2} \mathrm{~S}$ during fruit storage (Fig. 1A). An important goal for retailers and food service sectors is to delay fruit rot and enhance storability to deliver benefits to consumers. In this paper, we demonstrate that $\mathrm{H}_{2} \mathrm{~S}$ fumigation extended

Table 2. Effect of $\mathrm{H}_{2} \mathrm{~S}$ on the content of free amino acid in apple slices after $3 \mathrm{~d}$ of storage at $25^{\circ} \mathrm{C}$

\begin{tabular}{lcccccccr}
\hline \multicolumn{7}{c}{ Free amino acid content on an FW basis $\left(\mathrm{nmol} \cdot \mathrm{g}^{-1}\right)$} \\
\hline & Asp & Ser & Glu & His & Ala & Val & Cys & Total \\
$\mathrm{CK}$ & 457 & 1,548 & 77 & 5 & ND & ND & ND & 2,087 \\
$\mathrm{H}_{2} \mathrm{~S}$ & 609 & 1,679 & 91 & 36 & 96 & 12 & ND & 2,524 \\
\hline
\end{tabular}

Asp = aspartic acid; Ser = serine; Glu = glutamic acid; His = histidine; Ala = alanine; Val = valine; Cys = cysteine; $\mathrm{ND}=$ not detected; FW = fresh weight.

0 stands for fresh-cut apple slices; apple slices were treated with water $(\mathrm{CK})$ or $0.4 \mathrm{mmol} \cdot \mathrm{L}^{-1} \mathrm{H}_{2} \mathrm{~S}$ donor sodium hydrosulfide $\left(\mathrm{H}_{2} \mathrm{~S}\right)$ for $3 \mathrm{~d}$. the storage of fresh-cut apples by retarding the browning and decay of fruit at $25{ }^{\circ} \mathrm{C}$ (Figs. 1 and 2), implying that $\mathrm{H}_{2} \mathrm{~S}$ acts as a alleviating regulator in the senescence of postharvest fruit. Protein degradation is one of the significant characteristics of plant senescence, and protease is responsible for protein mobilization from dying cells into actively growing tissues (Foyer et al., 1994). In our work, $\mathrm{H}_{2} \mathrm{~S}$ treatment reduced the level of protease (Fig. 5I) and total free amino acids (Table 2), and a concomitantly higher content of soluble protein (Fig. 3B) compared with those of control was observed. All these data suggested a protective role of $\mathrm{H}_{2} \mathrm{~S}$ in maintaining the postharvest quality and delaying proteolysis by keeping higher contents of reducing sugar and soluble protein and lower level of protease and total free amino acids during fresh-cut apple storage.

Several researchers reported that overproduction of ROS such as the $\cdot \mathrm{O}_{2}^{-}$and $\mathrm{H}_{2} \mathrm{O}_{2}$ contributed to accelerated senescence of fresh-cut fruit ( $\mathrm{Hu}$ et al., 2014). The reactive nature of ROS is potentially harmful to all cellular components, including proteins, lipids, and nucleotides (Apel and Hirt, 2004) and oxidative damage caused by ROS has been universally observed during postharvest storage of vegetables and fruits (Gao et al., 2013; Li et al., 2014). Plants possess two principal ROS-scavenging systems (Mittler et al., 2004), one involving antioxidant enzymes including APX, CAT, DHAR, GR, POD, and SOD and the other natural antioxidants such as ascorbic acid, total phenolics, and flavonoids. APX, DHAR, and GR are the critical enzymes in the ascorbate-glutathione cycle and play vital roles in maintaining ascorbate and glutathione homeostasis in plants (Mittler et al., 2004). In the present study, we showed there were significantly decreased production of $\bullet_{2}^{-}, \mathrm{H}_{2} \mathrm{O}_{2}$; elevated levels of APX, CAT, GR, POD, and SOD activity; enhanced MdDHAR expression; and higher contents of antioxidants (ascorbic acid, total phenolics, and flavonoids) in $\mathrm{H}_{2} \mathrm{~S}$-treated apple slices (Figs. 3C-E, 4, 5A-E, and 6A), suggesting that $\mathrm{H}_{2} \mathrm{~S}$ might function in alleviating ROS damage via promoting the antioxidants content and the activities of antioxidant enzymes during fruit storage.
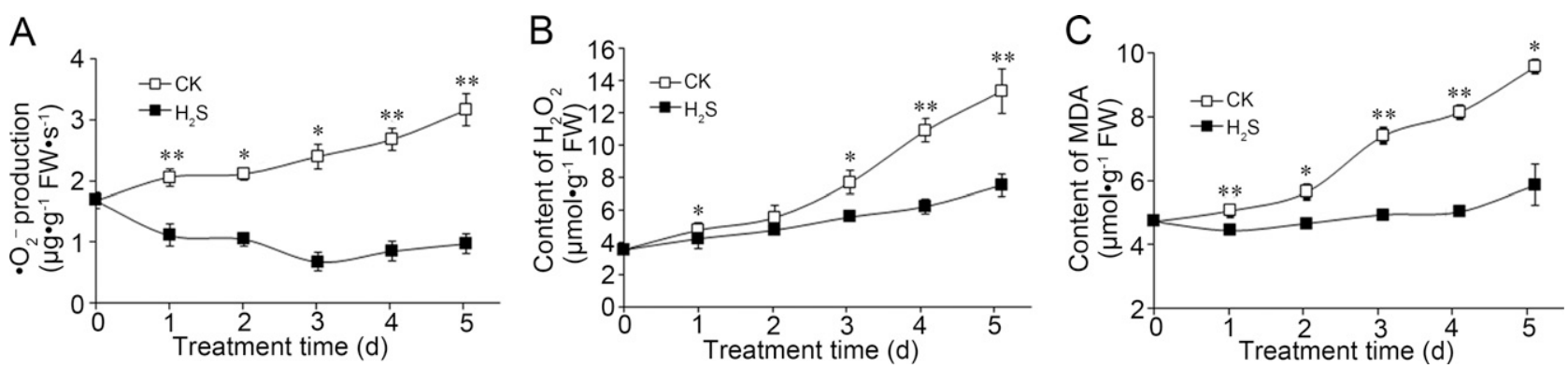

Fig. 4. Effects of hydrogen sulfide $\left(\mathrm{H}_{2} \mathrm{~S}\right)$ on $(\mathbf{A})$ superoxide anion $\left(\cdot \mathrm{O}_{2}^{-}\right)$production rate and contents of $(\mathbf{B})$ hydrogen peroxide $\left(\mathrm{H}_{2} \mathrm{O}_{2}\right)$, and $(\mathbf{C})$ malondialdehyde (MDA) in apple slices. Apple slices were fumigated with $0.4 \mathrm{mmol} \cdot \mathrm{L}^{-1} \mathrm{H}_{2} \mathrm{~S}$ donor sodium hydrosulfide aqueous solution $\left(\mathrm{H}_{2} \mathrm{~S}\right)$ with water as the control groups $(\mathrm{CK})$ for $0-5 \mathrm{~d}$. Data are presented as means $\pm \mathrm{SD}(\mathrm{n}=3)$. $\mathrm{FW}=$ fresh weight. 
A

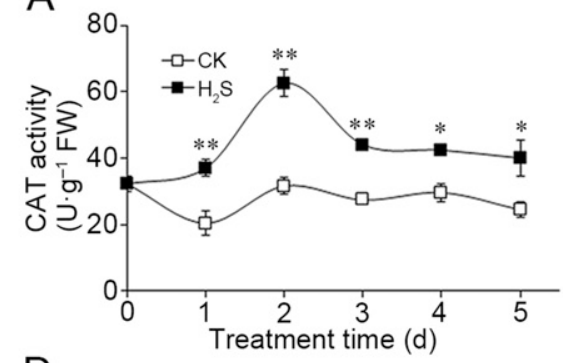

$\mathrm{D}$
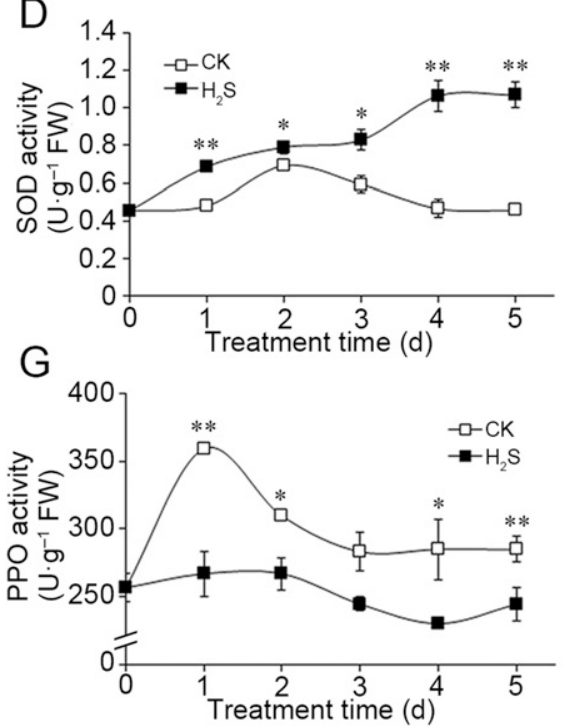

B

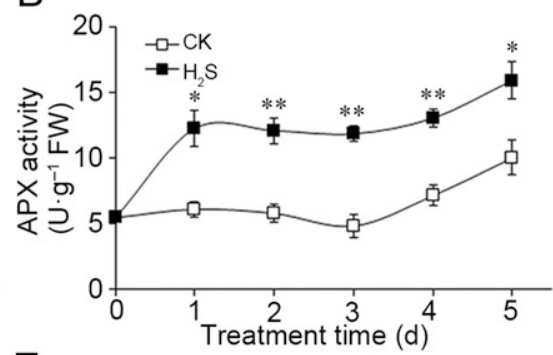

E
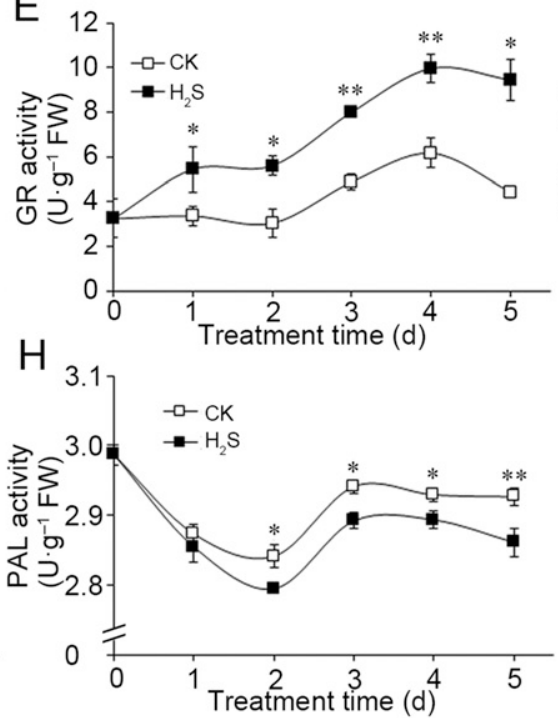

C
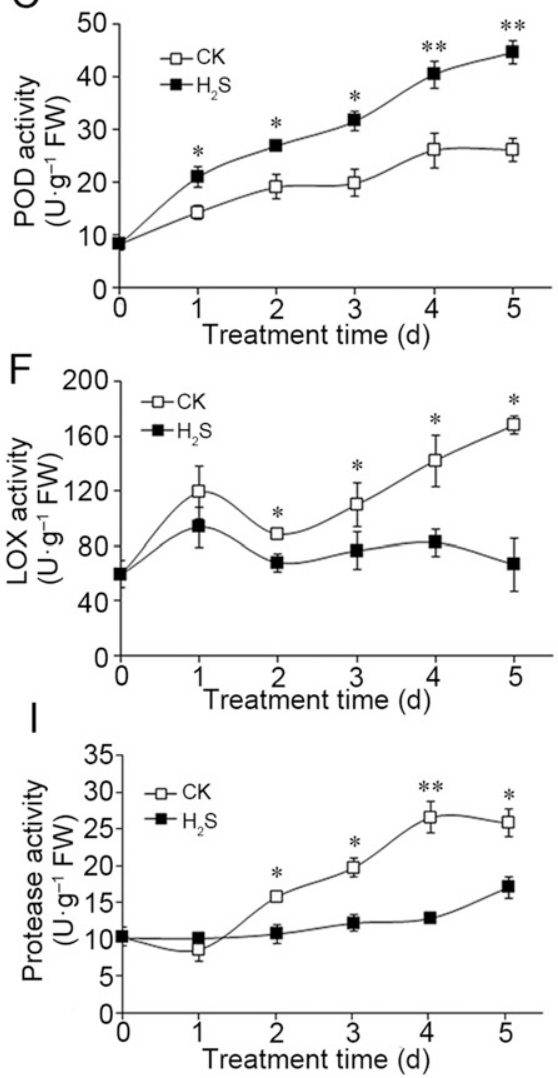

Fig. 5. Effects of hydrogen sulfide $\left(\mathrm{H}_{2} \mathrm{~S}\right)$ on the activities of (A) catalase (CAT); (B) ascorbate peroxidase (APX); (C) guaiacol peroxidase (POD); (D) superoxide dismutase (SOD); (E) glutathione reductase (GR); (F) lipoxygenase (LOX); (G) polyphenol oxidase (PPO); (H) phenylalanine ammonia lyase (PAL); and (I) protease in apple slices. Apple slices were fumigated with $0.4 \mathrm{mmol} \cdot \mathrm{L}^{-1} \mathrm{H}_{2} \mathrm{~S}$ donor sodium hydrosulfide aqueous solution ( $\mathrm{H}_{2} \mathrm{~S}$ ) with water as the control groups $(\mathrm{CK})$ for $0-5 \mathrm{~d}$. Data are presented as means $\pm \mathrm{SD}(\mathrm{n}=3) . \mathrm{FW}=$ fresh weight.
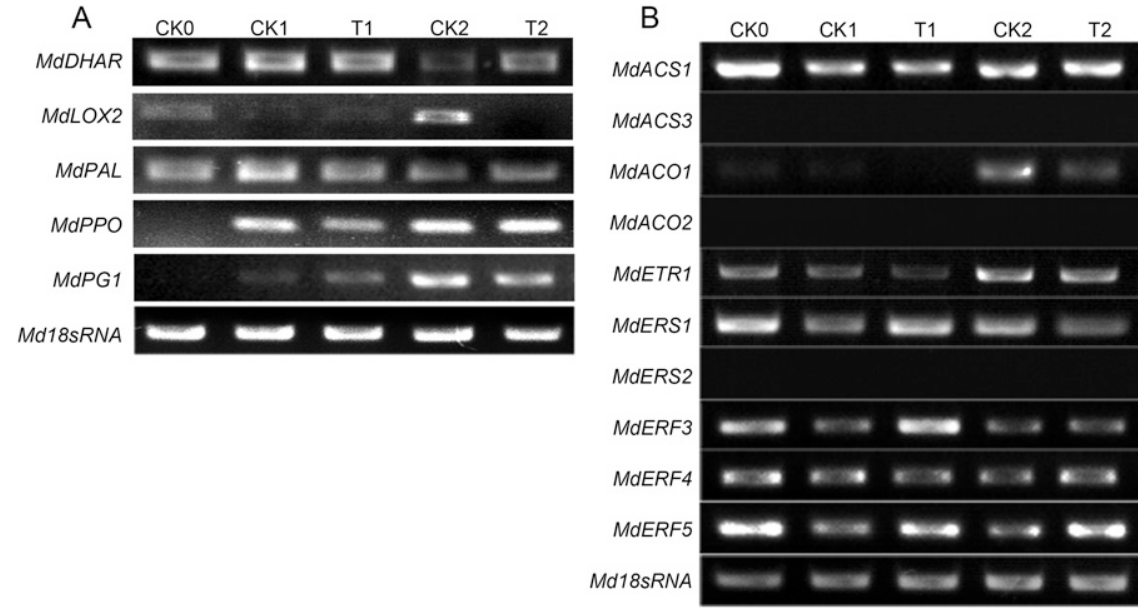

Fig. 6. Effects of hydrogen sulfide $\left(\mathrm{H}_{2} \mathrm{~S}\right)$ on the relative expression of senescence-related genes in apple slices. Apple slices were fumigated with $0.4 \mathrm{mmol} \cdot \mathrm{L}^{-1} \mathrm{H}_{2} \mathrm{~S}$ donor sodium hydrosulfide aqueous solution $\left(\mathrm{H}_{2} \mathrm{~S}\right)$ with water as the control groups (CK) for $0,1(\mathrm{CK} 1, \mathrm{~T} 1)$, and $2 \mathrm{~d}(\mathrm{CK} 2, \mathrm{~T} 2)$. The role of $\mathrm{H}_{2} \mathrm{~S}$ on the relative expression of (A) antioxidant enzyme genes and (B) ethylene-related genes in apple fruit were presented by reversed transcript polymerase chain reaction experiment. Md18sRNA was used as a control gene.

The senescence of fresh-cut apple is a complex and highly regulated process accompanied with lipid peroxidation. Thus, MDA content in apple slices was measured to provide an index of the structural integrity of membranes (Hu et al., 2014). LOX activity is positively correlated with lipid peroxidation in plant tissues (Hu et al., 2014). We found that LOX activity, as well as MDA content, were lower after $\mathrm{H}_{2} \mathrm{~S}$ fumigation of apple slices (Figs. 4C, 5F, and 6A), suggesting that $\mathrm{H}_{2} \mathrm{~S}$ reduced lipid peroxidation, thereby maintaining membrane integrity and contributing to a delay in fruit tissue senescence.
Enzymatic browning is an important indicator of quality deterioration that limits the storage life of fresh-cut fruit. Data in Figs. 1A and 2 show that fresh-cut apple slices browned quickly, while $\mathrm{H}_{2} \mathrm{~S}$ application sustained good visual appearance. PAL and PPO are involved in the synthesis of free phenolics and catalyze the oxidation of phenolics into brown pigments, and finally contribute to surface browning of fresh-cut fruit (Nguyen et al., 2003). As shown in Figs. 5G-H and 6A, the decreased PAL and PPO activities and gene expression were observed in $\mathrm{H}_{2} \mathrm{~S}$-fumigated apple slices compared with water control, implying that $\mathrm{H}_{2} \mathrm{~S}$ fumigation delayed enzymatic browning of fresh-cut apple surface. However, the higher level of phenolic compounds in $\mathrm{H}_{2} \mathrm{~S}$ fumigated slices (Fig. 3D) and lower PAL activity (Fig. $5 \mathrm{H}$ ) seem like a contradiction, which was also observed in the study of banana peel (Nguyen et al., 2003).

Ethylene plays a crucial role in the ripening and senescence of apple. To preliminarily understand the effect of $\mathrm{H}_{2} \mathrm{~S}$ on ethylene pathway, we studied the expression patterns of genes that are involved in ethylene biosynthesis (MdACS1, MdACS3, MdACO1, and $M d A C O 2)$ and signal transduction (MdETR1, MdERS1, MdERS2, MdERF3, MdERF4, and $M d E R F 5)$ in 'Fuji' apple. Endopolygalacturonase is a key enzyme involved in pectin dissolution, fruit softening and maturation 
(Hadfield and Bennett, 1998). Here, we found that $\mathrm{H}_{2} \mathrm{~S}$ application suppressed the expressions of MdACO1, MdERS1, MdETR1, and MdPG1 (on Day 2), suggesting a counteractive role of $\mathrm{H}_{2} \mathrm{~S}$ in ethylene biosynthesis and signaling (Fig. 6). Similarly, NO has been shown to transcriptionally repress the expressions of genes of ethylene biosynthesis enzymes, suggesting a similar mechanism in decreasing ethylene synthesis (Manjunatha et al., 2012).

As we reported before, the levels of endogenous $\mathrm{H}_{2} \mathrm{~S}$ in strawberry fruits treated with exogenous $\mathrm{H}_{2} \mathrm{~S}$ gas are $\approx 10-20 \%$ higher than those of control, suggesting the safety of $\mathrm{H}_{2} \mathrm{~S}$ application in postharvest fruit storage (Hu et al., 2012). In conclusion, this study shows that $\mathrm{H}_{2} \mathrm{~S}$ treatment not only helps to eliminate ROS overproduction, improve the antioxidant capacity, but also affects the expression of senescence-related genes in apple slices. Taken together, $\mathrm{H}_{2} \mathrm{~S}$ has the potential to maintain higher fruit quality and delay postharvest senescence of fresh-cut apple.

\section{Literature Cited}

AOAC. 1984. Vitamin C (ascorbic acid) in vitamin preparations and juices: 2,6-dichloroindophenol titrimetric method, p. 844-845. Official Methods of Analysis. Association of Official Analytical Chemists, Washington, DC.

Apel, K. and H. Hirt. 2004. Reactive oxygen species: Metabolism, oxidative stress, and signal transduction. Annu. Rev. Plant Biol. 55:373-399.

Beaudoin-Eagan, L.D. and T.A. Thorpe. 1985. Tyrosine and phenylalanine ammonia lyase activities during shoot initiation in tobacco callus cultures. Plant Physiol. 78:438-441.

Benjamin, N.D. and M.W. Montgomery. 1973. Polyphenol oxidase of Royal Ann cherries: Purification and characterization. J. Food Sci. 38:799-806.

Bradford, M.M. 1976. A rapid and sensitive method for the quantitation of microgram quantities of protein utilizing the principle of protein-dye binding. Anal. Biochem. 72:248-254.

Cao, S.F., Z.C. Hu, and B. Pang. 2010. Optimization of postharvest ultrasonic treatment of strawberry fruit. Postharvest Biol. Technol. 55:150-153.

Chen, J., F.H. Wu, W.H. Wang, C.J. Zheng, G.H. Lin, X.J. Dong, J.X. He, Z.M. Pei, and H.L. Zheng. 2011. Hydrogen sulphide enhances photosynthesis through promoting chloroplast biogenesis, photosynthetic enzyme expression, and thiol redox modification in Spinacia oleracea seedlings. J. Expt. Bot. 62:4481-4493.

Foyer, C.H., P. Descourvières, and K.J. Kunert. 1994. Protection against oxygen radicals: An important defence mechanism studied in transgenic plants. Plant Cell Environ. 17:507-523.

Gao, S.P., K.D. Hu, L.Y. Hu, Y.H. Li, Y. Han, H.L. Wang, K. Lv, Y.S. Liu, and H. Zhang. 2013. Hydrogen sulfide delays postharvest senescence and plays an antioxidative role in fresh-cut kiwifruit. HortScience 48:1385-1392.

Garcìa-Limones, C., A. Hervás, J.A. Navas-Cortés, R.M. Jiménez-Díaz, and M. Tena. 2002. Induction of an antioxidant enzyme system and other oxidative stress markers associated with compatible and incompatible interactions between chickpea (Cicer arietinum L.) and Fusarium oxysporum f. sp. ciceris. Physiol. Mol. Plant Pathol. 61:325-337.

García-Mata, C. and L. Lamattina. 2010. Hydrogen sulphide, a novel gasotransmitter involved in guard cell signalling. New Phytol. 188:977-984.

Gil, M.I., D.M. Holcroft, and A.A. Kader. 1997. Changes in strawberry anthocyanins and other polyphenols in response to carbon dioxide treatments. J. Agr. Food Chem. 45:1662-1667.

Hadfield, K.A. and A.B. Bennett. 1998. Polygalacturonases: Many genes in search of a function. Plant Physiol. 117:337-343.

Hu, H.L., W.B. Shen, and P.X. Li. 2013. Effects of hydrogen sulphide on quality and antioxidant capacity of mulberry fruit. Intl. J. Food Sci. Technol. 49:399-409.

Hu, L.Y., S.L. Hu, J. Wu, Y.H. Li, J.L. Zheng, Z.J. Wei, J. Liu, H.L. Wang, Y.S. Liu, and H. Zhang. 2012. Hydrogen sulfide prolongs postharvest shelf life of strawberry and plays an antioxidative role in fruits. J. Agr. Food Chem. 60: 8684-8693.

Hu, K.D., Q. Wang, L.Y. Hu, S.P. Gao, J. Wu, Y.H. Li, J.L. Zheng, Y. Han, Y.S. Liu, and H. Zhang. 2014. Hydrogen sulfide prolongs postharvest storage of fresh-cut pears (Pyrus pyrifolia) by alleviation of oxidative damage and inhibition of fungal growth. PLoS One 9:e85524.

Jia, Z.S., M.C. Tang, and J.M. Wu. 1999. The determination of flavonoid contents in mulberry and their scavenging effects on superoxide radicals. Food Chem. 64:555-559.

Johnston, J.W., E.W. Hewett, and M.L. Hertog. 2002. Postharvest softening of apple (Malus domestica) fruit: A review. N. Z. J. Crop Hort. Sci. 30:145-160.

Kays, S.J. 1991. Metabolic processes in harvested products, p. 75-142. In: S.J. Kays (ed.). Postharvest physiology of perishable plant products. Van Nostrand Reinhold, New York, NY.

Li, S.P., K.D. Hu, L.Y. Hu, Y.H. Li, A.M. Jiang, F. Xiao, Y. Han, Y.S. Liu, and H. Zhang. 2014. Hydrogen sulfide alleviates postharvest senescence of broccoli by modulating antioxidant defense and senescence-related gene expression. J. Agr. Food Chem. 62:1119-1129.

Li, Z.R., K.D. Hu, F.Q. Zhang, S.P. Li, L.Y. Hu, Y.H. Li, S.H. Wang, and H. Zhang. 2015. Hydrogen sulfide alleviates dark-promoted senescence in postharvest broccoli. HortScience 50:416-420.

Lin, Z.F., S.L. Zhong, and D. Grierson. 2009. Recent advances in ethylene research. J. Expt. Bot. 60:3311-3336.

Manjunatha, G., K.J. Gupta, V. Lokesh, L.A. Mur, and B. Neelwarne. 2012. Nitric oxide counters ethylene effects on ripening fruits. Plant Signal. Behav. 7:476-483.

McGuire, R.G. 1992. Reporting of objective color measurements. HortScience 27:1254-1255.
Miller, G.L. 1959. Use of dinitrosalicylic acid reagent for determination of reducing sugar. Anal. Chem. 31:426-428.

Mittler, R., S. Vanderauwera, M. Gollery, and F.V. Breusegem. 2004. Reactive oxygen gene network of plants. Trends Plant Sci. 9:490-498.

Nguyen, T.B.T., S. Ketsa, and W.G. van Doorn. 2003. Relationship between browning and the activities of polyphenoloxidase and phenylalanine ammonia lyase in banana peel during low temperature storage. Postharvest Biol. Technol. 30:187-193.

Pirie, A. and M.G. Mullins. 1976. Changes in anthocyanin and phenolics content of grapevine leaf and fruit tissues treated with sucrose, nitrate and abscisic acid. Plant Physiol. 58:468472.

Pristijono, P., R.B.H. Wills, and J.B. Golding. 2006. Inhibition of browning on the surface of apple slices by short term exposure to nitric oxide (NO) gas. Postharvest Biol. Technol. 42:256-259.

Raseetha, S., S.Y. Leong, D.J. Burritt, and I. Oey. 2013. Understanding the degradation of ascorbic acid and glutathione in relation to the levels of oxidative stress biomarkers in broccoli (Brassica oleracea L. italica cv. Bellstar) during storage and mechanical processing. Food Chem. 138:1360-1369.

Rausch, T. and A. Wachter. 2005. Sulfur metabolism: A versatile platform for launching defence operations. Trends Plant Sci. 10:503509.

Reimerdes, E.H. and H. Klostermeyer. 1976. Determination of proteolytic activities on casein substrates. Methods Enzymol. 45:26-28.

Rico, D., A.B. Martín-Diana, J.M. Barat, and C. Barry-Ryan. 2007. Extending and measuring the quality of fresh-cut fruit and vegetables: A review. Trends Food Sci. Technol. 18: 373-386.

Simpson, R.J., M.R. Neuberger, and T.Y. Liu. 1976. Complete amino acid analysis of proteins from a single hydrolysate. J. Biol. Chem. 251:1936-1940.

Surrey, K. 1964. Spectrophotometric method for determination of lipoxidase activity. Plant Physiol. 39:65-70.

Wang, R. 2002. Two's company, three's a crowd: Can $\mathrm{H}_{2} \mathrm{~S}$ be the third endogenous gaseous transmitter? FASEB J. 16:1792-1798.

Zhang, H., L.Y. Hu, K.D. Hu, Y.D. He, S.H. Wang, and J.P. Luo. 2008. Hydrogen sulfide promotes wheat seed germination and alleviates the oxidative damage against copper stress. J. Integr. Plant Biol. 50:1518-1529.

Zhang, H., S.L. Hu, Z.J. Zhang, L.Y. Hu, C.X. Jiang, Z.J. Wei, J. Liu, H.L. Wang, and S.T. Jiang. 2011. Hydrogen sulfide acts as a regulator of flower senescence in plants. Postharvest Biol. Technol. 60:251-257.

Zhang, H., J. Tang, X.P. Liu, Y. Wang, W. Yu, W.Y. Peng, F. Fang, D.F. Ma, Z.J. Wei, and L.Y. Hu. 2009. Hydrogen sulfide promotes root organogenesis in Ipomoea batatas, Salix matsudana, and Glycine max. J. Integr. Plant Biol. 51:1084-1094. 